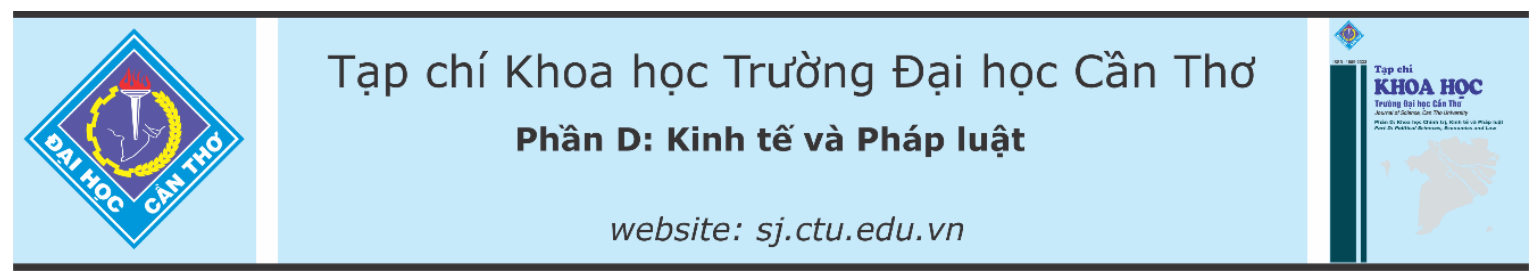

DOI:10.22144/ctu.jvn.2021.030

\title{
SỰ SẲN LÒNG THAM GIA ĐÓNG GÓP VÀO QUỸ TÍN DỤNG NộI Bộ CỦA THÀNH VIÊN HỢP TÁC XÃ NÔNG NGHIỆP TRÊN ĐỊA BÀN TỈNH VĨ̃NH LONG
}

\author{
Võ Hồng Tú* và Nguyễn Thuỳ Trang \\ Bộ môn Kinh tế - Xã họi Nông thôn, Khoa Phát triển Nông thôn, Truờng Đại học Cần Tho \\ "Nguoòi chịu trách nhiệm về bài viết: Võ Hồng Tú (email: vhtu@ctu.edu.vn)
}

\section{Thông tin chung:}

Ngày nhận bài: $12 / 08 / 2020$

Ngày nhận bài sưa: 17/09/2020

Ngày duyệt đăng: 27/02/2021

Title:

Willingness to pay for internal credit of agricultural cooperative members in Vinh Long province

\section{Tù khóa:}

Hồi quy OLS, hơp tác xã nông nghiệp, sư sắn lòng tham gia, tín dụng nội bộ

Keywords:

Agricultural cooperatives, internal credit, $O L S$ regression, willingness to participate

\begin{abstract}
The internal credit is one of the important services for agricultural cooperatives, contributing to improving the production and business performance of both cooperatives and members. Based on the current situations, there have not been any internal credits due to difficulties in financial capital in Vinh Long province. The study conducted focus group interviews with 29 agricultural cooperatives and face-to-face interviews with 244 members of the cooperatives. The research results show that the majority of cooperatives $(62.1 \%)$ and members $(81.97 \%)$ were willing to establish and pay for the internal credits. OLS regression results show that participation in training and participation in unions and mass organizations have positive relationship while production experience has a negative effect on willingness to participate and pay for the internal credits. The study also proposed some specific recommendations to establish and develop the internal credit systems for agricultural cooperatives in Vinh Long province.
\end{abstract}

\section{TÓM TẮT}

Quỹ tín dụng nội bộ (TDNB) là một trong nhũng dịch vu quan trọng đối với các hơp tác xã nông nghiệp (HTXNN), góp phần nâng cao hiệu quả sản xuất, kinh doanh của cả HTX và thành viên. Tù thực trạng các HTXNN trên địa bàn tỉnh Vĩnh Long, quỹ TDNB chura được thành lập do còn nhiều khó khăn về nguồn vốn tài chính. Kết quả phỏng vấn nhóm Hộ đồng quản trị của 29 HTXNN và 244 thành viên của các HTXNN cho thấy phần lớn Hội đồng quản trị HTXNN và thành viên đều có nguyện vọng thành lập quỹ TDNB, cu thể có đến 62,1\% các HTX đồng ý thành lập quỹ và $81,97 \%$ thành viên sẽ sẵn sàng tham gia vào quỹ TDNB. Kết quả hồi quy bằng phuoong pháp bình phưong bé nhất (OLS) cho thấy tham gia tâp huấn và tham gia vào hội, đoàn thể có ảnh hương tỷ lệ thuận trong khi kinh nghiệm sản xuất ảnh hưởng tỷ lệ nghịch đến sụ sẵn lòng tham gia đóng góp cho quỹ TDNB. Nghiên cứu cũng đã đề xuất một số kiến nghị cu thể để thành lập và phát triển quỹ TDNB cho các HTXNN trên địa bàn tinh Vinh Long. 


\section{MỞ ĐẦU}

Trong xu thế phát triển và hội nhập ngày càng sâu rộng vào nền kinh tế thế giới, Việt Nam đã và đang thực thi 13 hiệp định tự do thương mại và 3 hiệp định đang trong vòng đàm phán, gần đây nhất là hiệp định EVFTA và CPTPP (Mekong Connect, 2019). Điều này đồng nghĩa với việc các mặt hàng nông sản Việt Nam phải đạt tới những tiêu chuẩn, những đòi hỏi khắc khe về chất lượng, mẫu mã của thị trường, cùng với áp lực cạnh tranh giữa các nước ngày càng nhiều, nhất là trong lĩnh vực nông nghiệp (Hà Thị Thu Hà, 2017). Tuy nhiên, quy mô sản xuất nhỏ lẻ, manh mún đã gây rất nhiều khó khăn trong thực hiện các tiêu chuẩn và đáp ứng yêu cầu của thị trường.

Nghị quyết Trung ương 5 khóa IX về kinh tế tập thể (KTTT) nhận định đây là một phần thành kinh tế quan trọng, không chỉ đóng góp cho tăng trưởng kinh tế mà còn phát huy vai trò toàn diện về văn hóa, chính trị, xã hội. KTTT không chỉ là nguồn lực cho sự phát triển mà thông qua tổ chức đặc thù của nó là phương tiện để giảm chi phí, nâng cao hiệu quả hoạt động của các thành viên: hộ nông dân, người sản xuất nhỏ, các doanh nghiệp, các tổ chức, giúp các thành viên phát triển một cách bền vững (Dương Ngọc Thành và ctv., 2018; Khưu Bảo Châu, 2017; Huỳnh Kim Nhân, 2017; Dương Ngọc Thành và ctv., 2016; Bùi Thống Nhất, 2010).

Với tinh thần tự nguyện, tương trợ và giúp đỡ, liên kết nhau cùng sản xuất trên một diện tích, quy mô rộng lớn, sản xuất theo tiêu chuẩn, yêu cầu thị trường, KTTT còn giúp nông dân tiếp cận được các chính sách hỗ trợ về đào tạo, bồi dưỡng đội ngũ cán bộ quản lý, thành lập quỹ tín dụng nội bộ (TDNB), xây dựng và nâng cấp cơ sở hạ tầng, các dụng cụ/phương tiện sản xuất,... (Dương Ngọc Thành và ctv., 2018; Dương Ngọc Thành và ctv., 2016; Nguyễn Công Bình, 2011; Phan Trọng An, 2007; Phạm Thị Minh Nguyệt, 2006).

Theo số liệu báo cáo của Bộ Nông nghiệp và Phát triển Nông thôn (2019), toàn vùng Đồng bằng sông Cửu Long (ĐBSCL) năm 2018 có 1.803 hợp tác xã nông nghiệp (HTXNN) đang hoạt động. Vĩnh Long là một trong những tỉnh có số lượng HTXNN còn hạn chế, đến cuối năm 2019 toàn tỉnh có 94 HTXNN (Chi cục PTNT tỉnh Vĩnh Long, 2020). Theo Nguyễn Văn Tuấn (2019), Nguyễn Thanh Thửa (2018), Dương Ngọc Thành và ctv. (2018), Dương Ngọc Thành và $c t v$. (2016), Huỳnh Kim Nhân (2017), Khưu Bảo Châu (2017), Nguyễn Văn Đệ (2013) và Bùi Thống Nhất (2010), HTXNN trên địa bàn tỉnh Vĩnh Long nói riêng và khu vực ĐBSCL nói chung đã góp phần giải quyết nhiều vấn đề về khó khăn cho thành viên trong sản xuất, tiêu thụ, giải quyết việc làm cho lao động nông thôn,...Tuy nhiên, nhiều HTXNN cũng như các thành viên còn gặp nhiều khó khăn trong việc tiếp cận nguồn vốn vay chính thức với lãi suất ưu đãi vì không có tài sản thuế chấp. Do vậy, nhiều HTXNN và thành viên thiếu vốn để vận hành các hoạt động sản xuất, kinh doanh. Nhận thấy được thực tế này, một số HTXNN đã thành lập quỹ TDNB nhằm tạo nguồn vốn vay với lãi suất thấp cho các thành viên tiếp cận để đầu tư vào hoạt động sản xuất và kinh doanh, từ đó góp phần nâng cao thu nhập cho các thành viên $\mathrm{HTX}$ và tăng cường mối gắn kết gữa các thành viên lẫn nhau cũng như giữa thành viên và HTX. Với hình thức vay tín chấp, thủ tục nhanh gọn, lãi suất thấp, từ đó giúp thành viên HTX an tâm sản xuất, tránh những nhu cầu vay nóng từ bên ngoài. Tuy nhiên, số lượng HTX trên địa bàn tỉnh thực hiện dịch vụ TDNB còn ít và gặp rất nhiều khó khăn như số lượng thành viên tham gia đóng góp vào quỹ TDNB chưa cao, Hội đồng quản trị còn hạn chế về trình độ chuyên môn trong quản lý TDNB. Sự hạn chế này có thể do chưa có đánh giá đúng thực trạng về khả năng tham gia đóng góp của các thành viên.

Do vậy, nghiên cứu được thực hiện nhằm nghiên cứu đánh giá sự sẵn lòng tham gia, và các yếu tố ảnh hưởng đến sự sẵn lòng tham gia đóng góp của thành viên HTXNN trên địa bàn tỉnh vào quỹ TDNB để từ đó góp phần đề xuất giải pháp nâng cao hiệu quả hoạt động TDNB của HTXNN trên địa bàn tỉnh Vĩnh Long.

\section{PHƯƠNG PHÁP NGHIÊN CÚU}

\subsection{Mô hình và giả thuyết nghiên cứu}

Để thực hiện phân tích sự sẵn lòng đóng góp của thành viên HTXNN vào quỹ tín dụng nội bộ, nghiên cứu đặt giả định về nguồn vốn vay chỉ được sử dụng trong nội bộ HTX và để hỗ trợ các thành viên trong HTX, đặc biệt là thành viên có điều kiện khó khăn về tài chính để tiếp cận vốn vay theo hình thức xoay vòng. Nguồn vốn góp của từng thành viên sẽ được ghi sổ và hưởng được lãi suất theo quy định của đại hội thành viên nhưng chỉ bằng hoặc thấp hơn so với lãi suất gửi ngân hàng.

Để phân tích các yếu tố ảnh hưởng đến sự sẵn lòng tham gia đóng góp vào quỹ TDNB, các nghiên cứu trước đây cho thấy thu nhập là một trong những yếu tố quan trọng quyết định đển sự sẳn lòng và mức độ tham gia đóng góp (Khai and Yabe, 2015; Kotchen, 2005; Kontoleon and Yabe, 2006; Nguyễn 
Thùy Trang và Võ Hồng Tú, 2016; Nguyễn Văn Song và $c t v ., 2011)$. Giới tính cũng là một yếu tố quan trọng có ảnh hưởng đến sự sẵn lòng tham gia đóng góp của thành viên cũng như hành vi của người tiêu dùng (Nguyễn Thùy Trang và Võ Hồng Tú, 2016). Tham gia trong các tổ chức và tập huấn về kiến thức hợp tác xã cũng là một trong những yếu tố quan trọng có ảnh hưởng đến quyết định cũng như sự sã̃n lòng tham gia đóng góp do nhận thức được các lợi ích từ hoạt động này (Tu et al., 2018; Nguyễn Văn Song và $c t v ., 2011)$. Bên cạnh đó, nghiên cứu cũng muốn tiến hành kiểm định các giả thuyết về sự khác biệt giữa các nhóm thành viên có lĩnh vực sản xuất khác nhau. Tổng hợp các biến được sử dụng trong mô hình hồi quy được trình bày ở Bảng 1 .

\subsection{Phương pháp thu thập số liệu}

Để đảm bảo tính đại diện cao, nghiên cứu thực hiện phỏng vấn nhóm 29 HTXNN tại 7 trong 8 đơn vị hành chính của tỉnh Vĩnh Long, ngoại trừ thành phố Vĩnh Long.

Tại 29 HTXNN, nghiên cứu thực hiện phỏng vấn nhóm Hội đồng quản trị để nắm được thực trạng hoạt động TDNB và định hướng trong đề xuất giải pháp. Bên cạnh đó, nghiên cứu đã thực hiện phỏng vấn bằng bảng hỏi cấu trúc với khoảng 10 thành viên/HTX đối với HTX có số lượng đông và phỏng vấn tổng thể đối với trường hợp có số lượng thành viên ít hơn 10 .
Trong 29 HTXNN, để đảm bảo tính đại diện cao, nghiên cứu chọn HTX với nhiều lĩnh vực sản xuất khác nhau, gồm trồng trọt, chăn nuôi và thủy sản. Nghiên cứu thực hiện chọn mẫu ngẫu nhiên dựa vào danh sách cung cấp từ Hội đồng quản trị.

Tổng mẫu của thành viên HTX được phỏng vấn là 244 quan sát, trong đó, HTX lúa gạo với 114 quan sát, HTX sản xuất sản phẩm rau, củ các loại là 32 quan sát; HTX cây ăn trái là 87 quan sát; HTX thủy sản là 11 quan sát.

\subsection{Phương pháp phân tích số liệu}

Để xác định các yếu tố ảnh hưởng đến sự sẵn lòng đóng góp vào quỹ TDNB của các thành viên HTXNN tỉnh Vĩnh Long, nghiên cứu sử dụng mô hình hồi quy OLS, mô hình có dạng như sau:

$$
Y_{i}=\beta_{0}+\beta_{1} X_{1}+\beta_{2} X_{2}+\cdots+\beta_{i} X_{i}+\varepsilon_{i}
$$

$Y_{i}$ : biến phụ thuộc, thể hiện mức sẵn lòng đóng góp, đơn vị 1.000 đồng/tháng

$X_{1}, X_{2}, X_{\mathrm{i}}$ : là các biến độc lập có ảnh hưởng đến $Y$, các biến được mô tả ở Bảng 1 sau.

$\beta_{1}, \beta_{2}, \beta_{\mathrm{i}}$ : là các tham số cần ước lượng, tham số này cho biết ảnh hưởng của từng biến độc lập lên mức sẵn lòng đóng góp trong điều kiện các biến còn lại cố định.

$\varepsilon_{i}$ : là sai số của mô hình hồi quy

\section{Bảng 1. Mô tả biến sử dụng trong mô hình hồi quy}

\begin{tabular}{lclc}
\hline \multicolumn{1}{c}{ Tên biến } & Ký hiệu & Diễn giải & Kỳ vọng \\
\hline Mức sắn lòng đóng góp & $\mathrm{Y}$ & Mức sẵn lòng đóng góp, ngàn đồng/tháng & \\
Giới tính & $\mathrm{X}_{1}$ & Biến giả, $1=$ nam, $0=$ nữ & + \\
Sản xuất rau màu & $\mathrm{X}_{2}$ & Biến giả, $1=$ rau màu, $0=$ khác & + \\
Sản xuất lúa & $\mathrm{X}_{3}$ & Biến giả, $1=$ sản xuất lúa, $0=$ khác & + \\
Sản xuất cây ăn trái & $\mathrm{X}_{4}$ & Biến giả, $1=$ sản xuất cây ăn trái, $0=$ khác & + \\
Tham gia tập huấn & $\mathrm{X}_{5}$ & Biến giả, $1=$ có, $0=$ không & + \\
Kinh nghiệm sản xuất & $\mathrm{X}_{6}$ & Năm tham gia vào HTX & + \\
Thu nhập hộ gia đình & $\mathrm{X}_{7}$ & Thu nhập trong năm, ngàn đồng/năm & + /- \\
Tham gia tồ chức & $\mathrm{X}_{8}$ & Biến giả, $1=$ có, $0=$ không & + \\
\hline
\end{tabular}

\section{KÊT QUẢ NGHIÊN CƯU}

\subsection{Thực trạng hoạt động của các HTXNN tỉnh Vĩnh Long}

\subsubsection{Thực trạng thành lập và phát triển}

Theo báo cáo của Chi cục Phát triển Nông thôn tỉnh Vĩnh Long (2020), toàn tỉnh Vĩnh Long có 94 HTXNN và 1 Liên hiệp HTX, chỉ chiếm khoảng 5\% tổng số lượng HTXNN khu vực ĐBSCL. Tổng số lượng thành viên của HTXNN là 2.167 thành viên, trung bình chỉ khoảng 23 thành viên/HTX, thấp hơn rất nhiều so với mức trung bình chung của khu vực là 130 thành viên. Tổng số lao động của HTXNN là 3.056 lao động và tổng vốn điè̀u lệ trên 56,28 tỷ đồng. Trong tồng số 94 HTX và Liên hiệp HTX, có 29 HTX lúa gạo, 22 HTX cây ăn trái, 14 HTX rau màu, 12 HTX HTX chăn nuôi/thủy sản, 01 Liên hiệp HTX lúa gạo và 17 HTX dịch vụ tổng hợp. Tổng diện tích sản xuất của các HTX nông nghiệp là 1.829 ha, có trên 88 ha ao nuôi và trên 100 lồng bè thủy sản. 
Bảng 2. Tổng hợp tình hình phát triển HTXNN Vĩnh Long giai đoạn 2011 - 2019

\begin{tabular}{lrrrrrrrrr}
\hline Tiêu chí & $\mathbf{2 0 1 1}$ & $\mathbf{2 0 1 2}$ & $\mathbf{2 0 1 3}$ & $\mathbf{2 0 1 4}$ & $\mathbf{2 0 1 5}$ & $\mathbf{2 0 1 6}$ & $\mathbf{2 0 1 7}$ & $\mathbf{2 0 1 8}$ & $\mathbf{2 0 1 9}$ \\
\hline Số lượng HTXNN & 37 & 37 & 36 & 35 & 30 & 33 & 57 & 74 & 94 \\
Tổng diện tích (ha) & 972 & 972 & 952 & 874 & 759 & 750 & 1.056 & 1.173 & 1.829 \\
Số lượng thành viên & 965 & 965 & 950 & 778 & 775 & 648 & 1.017 & 1.602 & 2.167 \\
\hline
\end{tabular}

Nguồn: Chi cục Phát Triển Nông Thôn tỉnh Vĩnh Long, 2020

Các HTXNN ở tỉnh Vĩnh Long nhìn chung còn nhiều hạn chế, yếu kém, hoạt động còn nhiều khó khăn, trong đó một số hạn chế, khó khăn chính như quy mô HTX nhỏ, thiếu cơ sở vật chất (trụ sở, nhà kho, sân phơi,...) nguồn lực ít. Đa phần hoạt động dịch vụ hỗ trợ thành viên là chính, chưa hoạt động theo loại hình tập trung. Năng lực, trình độ của bộ máy quản trị thấp, chưa đáp ứng yêu cầu phát triển, sản phẩm của nhiều HTX chưa đạt chuẩn, chưa có thương hiệu nên thiếu sức cạnh tranh,...

Trong những năm gần đây, nhiều HTX nông nghiệp tỉnh Vĩnh Long đã bước đầu liên kết với các Doanh nghiệp trong đầu tư sản xuất, tiêu thụ sản phẩm và có giá trị gia tăng khá ổn định trong từng khâu liên kết, hiệu quả mang lại từ liên kết khá tích cực. Tuy nhiên, các liên kết của HTX đã và đang thực hiện còn nhỏ lẻ, chưa liên kết chặt chẽ thành chuỗi, HTX tự tìm đối tác liên kết nên tính liên kết chưa chặt, hiệu quả chưa cao và thiếu tính bền vững. Chính vì vậy, nhằm gia tăng giá trị nông sản, nâng cao hiệu quả hoạt động của HTX, cải thiện thu nhập và đời sống thành viên, người lao động, việc liên kêt xây dựng chuỗi liên kết sản xuất gắn với tiêu thụ sản phẩm của các HTXNN tỉnh Vĩnh Long hiện nay là một nhu cầu cấp bách và là xu thế phát triển tất yếu.

\subsubsection{Phân loai HTXNN}

Công tác đánh giá, phân loại HTX nói chung và HTXNN nói riêng là hoạt động mang tính chất quản lý Nhà nước ở các ngành, các cấp theo quy định, đây là hoạt động thường xuyên hàng năm. Việc phân loại HTX hàng năm là việc làm rất quan trọng đối với các cơ quan quản lý trong việc giám sát và hỗ trợ kịp thời cho các tổ chức này hoạt động ngày càng chất lượng và hiệu quả. Theo Dương Ngọc Thành (2018), phân loại HTXNN là công tác thường xuyên của hệ thống quản lý nhà nước, nhằm rà soát và đánh giá công tác hoạt động của HTX trong năm để thấy được hiệu quả hoạt động của HTX nhằm có hướng khắc phục những hạn chế, yếu kém trong một năm hoạt động của cơ quan quản lý HTX địa phương.

Qua kết quả khảo sát 29 HTXNN trên địa bàn tỉnh Vĩnh Long (Bảng 3) kết hợp với các tiêu chí đánh giá theo thông tư số 09/2017/TT-BNN\&PTNT ngày $17 / 04 / 2017$, có $34,5 \%$ các HTXNN trên địa bàn khảo sát hoạt động được đánh giá mức trung bình, 34,5\% thuộc nhóm hoạt động mạnh và 31,0\% HTXNN hoạt động yếu/kém. Kết quả này cho thấy tình hình hiệu quả hoạt động của các HTXNN tỉnh Vĩnh Long còn khá thấp và kết quả này cũng khá tương đồng với các tỉnh khác của khu vực ĐBSCL. Theo số liệu báo cáo của của Hoàng Tuấn (2019), tỷ lệ HTXNN có hiệu quả hoạt động được xếp hạng trung bình và yếu kém chiếm khoảng $70 \%$.

\section{Bảng 3. Phân loại HTXNN trên địa bàn tỉnh Vĩnh Long}

\begin{tabular}{lrr}
\hline Chỉ tiêu & $\begin{array}{r}\text { Số } \\
\text { lượng }\end{array}$ & $\begin{array}{r}\text { Tỷ } \\
\text { lệ(\%) }\end{array}$ \\
\hline HTX hoạt động mạnh & 10 & 34,5 \\
HTX hoạt động trung bình & 10 & 34,5 \\
HTX hoạt động yếu/ kém & 9 & 31,0 \\
\hline Tổng & 29 & 100,0 \\
\hline
\end{tabular}

Nguồn: Số liệu khảo sát HTXNN năm 2018, n=29

\subsubsection{Diện tích đất của HTXNN}

Đất là một yếu tố quan trọng quyết định đến quy mô và hiệu quả hoạt động cũng như tiềm năng và năng lực liên kết với các doanh nghiệp trong cung ứng vật tư đầu vào và bao tiêu sản phẩm đầu ra (Nguyễn Văn Tuấn, 2019). Bảng 4 cho thấy tổng diện tích đất trung bình của một HTXNN là 31,9 ha và HTXNN có diện tích đất lớn nhất là 188,4 ha, nhỏ nhất là 2 ha. Bảng 4 cũng cho thấy HTXNN có diện tích dưới 15 ha chiếm tỷ lệ cao nhất, khoảng 41,4\%. Quy mô hoạt động của các HTXNN trên địa bàn tỉnh Vĩnh Long còn nhỏ lẻ, gây khó khăn trong liên kết chuỗi giá trị và đáp ứng nhu cầu thị trường.

\section{Bảng 4. Diện tích đất sản xuất của HTXNN}

\begin{tabular}{lrr}
\hline Chỉ tiêu & Tần số & Tỷ lệ (\%) \\
\hline Dưới 15 ha & 12 & 41,4 \\
Từ 15 ha đến 32 ha & 8 & 27,6 \\
Từ 33 ha đến 78 ha & 7 & 24,1 \\
Trên 78 ha & 2 & 6,9 \\
\hline Tổng & 29 & 100,0 \\
Trung bình & & 31,9 \\
Giá trị nhỏ nhất & & 2,0 \\
Giá trị lớn nhất & & 188,4 \\
Độ lệch chuẩn & & 38,95 \\
\hline
\end{tabular}

Nguồn: Số liệu khảo sát HTXNN năm 2018, n=29 


\subsubsection{Quy mô hoạt động của HTXNN}

Quy mô hoạt động của HTXNN là tiêu chí quan trọng phản ánh năng lực, hiệu quả hoạt động và tiềm năng về thị trường mục tiêu. Trong tổng số 29 HTXNN quan sát, có 19 HTXNN hoạt động trong quy mô liên tỉnh, chiếm tỷ lệ 65,6 \% (Bảng 5). Tuy nhiên, còn một bộ phần lớn các HTXNN tỉnh Vĩnh Long có quy mô hoạt động dưới cấp huyện, điều này cho thấy thị trường hoạt động của một bộ phận HTXNN còn rất hạn chế.

\section{Bảng 5. Quy mô hoạt động sản xuất HTXNN}

\begin{tabular}{lrr}
\hline Đặc điểm & Số lượng & Tỷ lệ (\%) \\
\hline Quy mô ấp & 1 & 3,4 \\
Quy mô liên ấp & 1 & 3,4 \\
Quy mô xã & 1 & 3,4 \\
Quy mô liên xã & 2 & 6,9 \\
Quy mô huyện & 0 & 0,0 \\
Quy mô liên huyện & 4 & 13,9 \\
Quy mô tỉnh & 1 & 3,4 \\
Quy mô liên tỉnh & 19 & 65,6 \\
\hline Tồng & 29 & 100,0 \\
\hline
\end{tabular}

Nguồn: Số liệu khảo sát HTXNN năm 2018, n=29
Tóm lại, theo kết quả đánh giá chung, thị trường và địa bàn hoạt động của một bộ phận HTXNN tỉnh Vĩnh Long còn rất hạn chế. Điè̉u này cho thấy nhu cầu mở rộng thị trường và xúc tiến thương mại cho các HTXNN là rất cần thiết để góp phần nâng cao hiệu quả hoạt động cho các HTX.

\subsubsection{Hoạt động dịch vu trong HTXNN}

Dịch vụ của HTXNN là một tiêu chí quan trọng quyết định đến hiệu quả hoạt động của HTXNN và phục vụ phát triển cộng đồng. Bảng 6 cho thấy trong tồng số 29 HTXNN được nghiên cứu, có đến 24 (chiếm 82,8\%) HTXNN chỉ hoạt động đơn dịch vụ. HTXNN có từ 2 đến 3 dịch vụ chiểm tỷ lệ $13,8 \%$. Qua đó, cho thấy số dịch vụ hoạt động trong HTXNN còn rất ít, đa phần các HTXNN hoạt động dịch vụ tiêu thụ sản phẩm và cung ứng vật tư nông nghiệp là chính. Có 22 HTXNN cung cấp dịch vụ tiêu thụ sản phẩm, 7 HTXNN có dịch vụ cung ứng vật tư nông nghiệp và chỉ có 3 HTXNN tham gia vào hoạt động dịch vụ giống cây trồng, vật nuôi (Bảng 6). Kết quả nghiên cứu này cho thấy HTXNN chủ yếu tập trung vào dịch vụ tiêu thụ đầu ra của sản phẩm, các dịch vụ khác còn rất hạn chế. Kết quả này cho thấy tiềm năng về phát triển dịch vụ trong HTXNN tỉnh Vĩnh Long còn rất lớn.

Bảng 6. Dịch vụ của HTXNN tỉnh Vĩnh Long

\begin{tabular}{|c|c|c|}
\hline Số dịch vụ & Số lượng HTX & Tỷ lệ (\%) \\
\hline Không dịch vụ & 1 & 3,4 \\
\hline Đơn dịch vụ & 24 & 82,8 \\
\hline Từ 2 đến 3 dịch vụ & 4 & 13,8 \\
\hline Tổng & 29 & 100,0 \\
\hline Các dịch vụ & & Số lượng HTX \\
\hline Dịch vụ làm đất/thủy lợi & & 0 \\
\hline Dịch vụ tư vấn/thú y & & 0 \\
\hline Dịch vụ giống cây trồng, vật nuôi & & 3 \\
\hline Dịch vụ cung ứng vật tư nông nghiệp & & 7 \\
\hline Kinh doanh thương mại/vận chuyên & & 0 \\
\hline Dịch vụ tiêu thụ sản phẩm & & 22 \\
\hline Dịch vụ chế biến & & 0 \\
\hline Tín dụng nội bộ & & 0 \\
\hline
\end{tabular}

Nguồn: Số liệu khảo sát HTXNN năm 2018, n=29

\subsubsection{Nguồn vốn góp và vốn điều lệ của HTXNN}

Vốn điều lệ và vốn góp là nguồn lực quan trọng quyết định đến hiệu quả hoạt động của các HTXNN tỉnh Vĩnh Long. Kết quả nghiên cứu cho thấy mức vốn điều lệ trung bình của các HTXNN được nghiên cứu là 223 triệu đồng, trong đó vốn góp chỉ đạt 211 triệu đồng. Mức vốn này nhìn chung là khá hạn chế để phục vụ cho nhu cầu hoạt động và phát triển của các HTXNN tỉnh Vĩnh Long. 
Bảng 7. Tình hình vốn điều lệ và vốn góp của HTXNN

\begin{tabular}{lrrrr}
\hline \multirow{2}{*}{ Nguồn vốn (1.000 đồng) } & \multicolumn{2}{c}{ Vốn điều lệ } & \multicolumn{2}{c}{ Vốn đã góp } \\
\cline { 2 - 5 } & Tần số & Tỷ lệ & Tần số & Tỷ lệ \\
\hline$<147.000$ & 9 & 31,00 & 12 & 41,4 \\
$147.000-224.000$ & 16 & 55,20 & 14 & 48,3 \\
$225.000-772.000$ & 3 & 10,35 & 2 & 6,9 \\
$>772.000$ & 1 & 3,45 & 1 & 3,4 \\
\hline Tổng & 29 & 100,00 & 29 & 100,0 \\
\hline Trung bình & & 223.900 & & 211.500 \\
Giá trị nhỏ nhất & & 70.000 & & 55.000 \\
Giá trị lớn nhất & & 1.320 .000 & & 1.320 .000 \\
Độ lệch chuẩn & & 227.230 & & 230.040 \\
\hline
\end{tabular}

Nguồn: Số liệu khảo sát HTXNN năm 2018, n=29

\subsection{Sự sẵn lòng tham gia và đóng góp vào quỹ TDNB của HTXNN và thành viên}

Nhìn chung, các HTXNN trên địa bàn tỉnh Vĩnh Long chưa có hoạt động quỹ TDNB do còn nhiều khó khăn và thiếu thốn trong cơ sở vật chất, trụ sở làm việc, nguồn tài chính không đủ thành lập quỹ. Mặc khác, thành viên tham gia còn hạn chế, chưa có lòng tin nhiều vào HTXNN và chưa hiểu rõ về lợi ích cũng như quy trình thực hiện quỹ TDNB. Tuy nhiên, theo kết quả phỏng vấn nhóm Hội đồng quản trị của 29 HTXNN, có đến $62,1 \%$ các HTX đồng ý thành lập quỹ TDNB.
Đối với kết quả phỏng vấn thành viên, nghiên cứu cũng cho thây có đến $81,97 \%$ thành viên được phỏng vấn trả lời sẽ sẵn sàng tham gia vào quỹ TDNB. Có khoảng 18,03\% tỷ lệ thành viên không đồng ý tham gia vào quỹ TDNB là do có đủ vốn sản xuất nên không có nhu cầu vay vốn từ quỹ TDNB, chưa có lòng tin vào hiệu quả hoạt động/quản lý của HTXNN, một số thành viên không có khả năng góp vốn và lo lắng về những rủi ro khi họ tham gia vào quỹ TDNB.

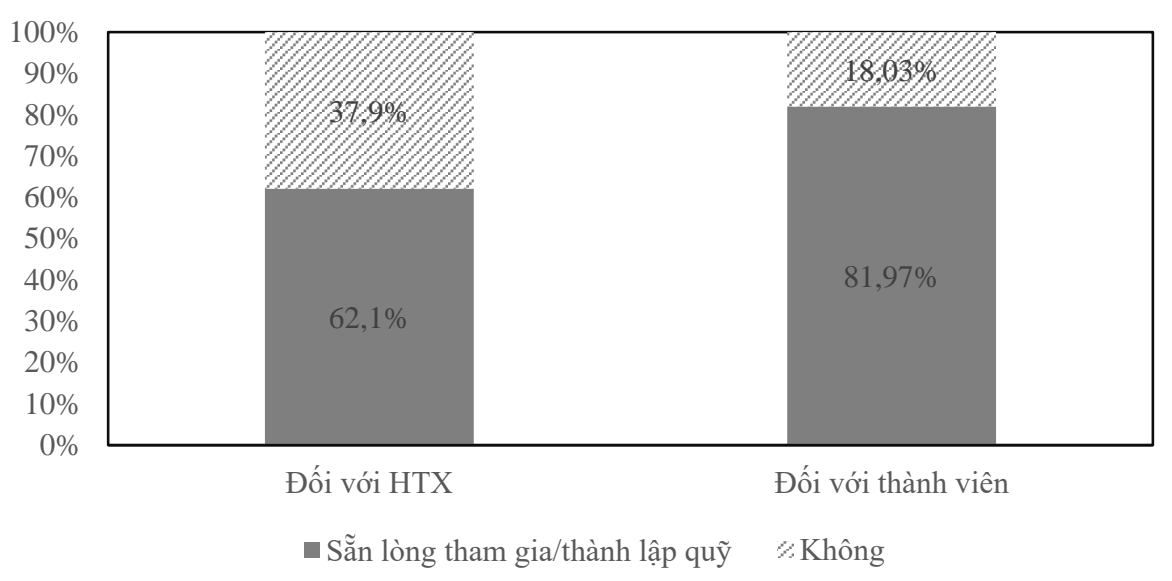

Hình 1. Sự sã̃n lòng tham gia của HTXNN và thành viên để thành lập quỹ TDNB Nguồn: Số liệu khảo sát HTXNN năm 2018, n=244

Để xác định các yếu tố ảnh hưởng đến sự sẵn lòng tham gia đóng góp của thành viên $\mathrm{HTXNN}$ vào quỹ TDNB, mô hình hồi quy OLS được sử dụng để xác định các yếu tố ảnh hưởng đến sự sẵn lòng đóng góp. Các biến độc lập được sử dụng trong mô hình được thống kê mô tả ở Bảng 8. 
Bảng 8. Mô tả các biến độc lập trong mô hình hồi quy

\begin{tabular}{llrr}
\hline Biến độc lập & Giải thích & Trung bình & Độ lệch chuẩn \\
\hline 1. Giới tính & Biến giả, 1=nam; 0=nữ & 0,94 & 0,24 \\
2. Nhân khẩu & Số thành viên (người) & 4,57 & 1,42 \\
3. Tham gia tập huấn & Biến giả, 1=có; 0=không & 0,99 & 0,11 \\
4. Kinh nghiệm sản xuất & Số năm tham gia sản xuất (năm) & 19,80 & 12,57 \\
5. Thu nhập của nông hộ & Thu nhập (1000 đồng/năm) & 354.568 & 658.550 \\
6. Diện tích sản xuất & Diện tích đất sản xuất (ha) & 1,32 & 2,22 \\
7. Tham gia tổ chức & Biến giả, 1=có; 0=không & 0,22 & 0,42 \\
8. Sản xuất rau màu & Biến giả, 1=rau màu; 0=khác & 0,13 & 0,34 \\
9. Sản xuất lúa & Biến giả, 1=lúa; 0=khác & 0,47 & 0,50 \\
10. Sản xuất cây ăn trái & Biến giả, 1=cây ăn trái; 0=khác & 0,36 & 0,48 \\
\hline
\end{tabular}

Nguồn: Kết quả khảo sát HTXNN năm 2018, n=244

Trước khi xác định các yếu tố ảnh hưởng đến sự sẵn lòng đóng góp của thành viên vào quỹ TDNB, thống kê mô tả về mức sẵn lòng đóng góp của thành viên HTXNN được trình bày cụ thể ở Bảng 9 . Sự sẵn lòng đóng góp của người dân đối với mức giá bid càng cao sẽ có xu hướng càng giảm (Nguyễn Thùy Trang và Võ Hồng Tú, 2016). Tuy nhiên, kết quả nghiên cứu cho thấy sự sẵn lòng đóng góp có sự khác nhau lớn giữa các nhóm thành viên thuộc các lĩnh vực sản xuất khác nhau, chẳng hạn, các thành viên thuộc HTXNN lĩnh vực thủy sản và cây ăn trái có mức sẵn lòng đóng góp lớn hơn. Điều này có thể được giải thích là do yêu cầu nguồn vốn đầu tư từ các hoạt động sản xuất này lớn hơn. Bảng 10 cũng cho thấy mức sẵn lòng đóng góp cao nhất là 151300 ngàn đồng/tháng (chiếm 31,56\%) và 451-600 ngàn đồng/tháng (chiếm 23,77\%). Nhìn chung, mức sẵn lòng đóng góp của các thành viên rất khác nhau trong từng lĩnh vực sản xuất, do vậy hình thức vận đóng đóng góp quỹ hàng tháng có thể tùy theo khả năng tài chính của từng thành viên trong HTX.

\section{Bảng 9. Sự sẵn lòng đóng góp của thành viên HTXNN}

\begin{tabular}{|c|c|c|c|c|c|c|c|}
\hline \multirow{2}{*}{ Lĩnh vực } & \multirow{2}{*}{$\mathbf{n}$} & \multicolumn{6}{|c|}{ Mức phí đóng góp (1.000 đồng/tháng) } \\
\hline & & $\mathbf{0}$ & $100-150$ & 151-300 & $301-450$ & 451-600 & $601-1.000$ \\
\hline Lúa & 114 & 10 & 19 & 46 & 6 & 22 & 11 \\
\hline Cây ăn trái & 87 & 22 & 11 & 16 & 3 & 27 & 8 \\
\hline Rau màu & 32 & 11 & 4 & 13 & 0 & 4 & 0 \\
\hline Thủy sản & 11 & 1 & 0 & 2 & 2 & 5 & 1 \\
\hline Tổng & 244 & 44 & 34 & 77 & 11 & 58 & 20 \\
\hline Tỷ trọng & 100 & 18,03 & 13,93 & 31,56 & 4,51 & 23,77 & 8,20 \\
\hline
\end{tabular}

Nguồn: Kết quả khảo sát năm 2018, $n=244$

Trước khi thực hiện mô hình hồi quy OLS, nghiên cứu sẽ tách ra các quan sát mà thành viên không sẵn lòng tham gia đóng góp do không tin tưởng vào mô hình hoặc cách thức quản lý/vận hành quỹ TDNB (non-zero) hay nói cách khác là những thành viên này có sẵn lòng đóng góp nhưng cần mô hình quản lý quỹ TDNB hiệu quả và minh bạch. Kết quả nghiên cứu cho thấy có 12 thành viên thuộc nhóm này và được tách ra khỏi mô hình hồi quy OLS. Kết quả mô hình hồi quy OLS được trình bày cụ thể ở Bảng 11.

Kết quả phân tích cho thấy giá trị Prob $>\mathrm{F}$ của mô hình là $0,000<\alpha=1 \%$, mô hình có ý nghĩa thống kê ở mức $1 \%$, cho thấy mô hình có ít nhất một biến độc lập ảnh hưởng đến giá trị đóng góp vào quỹ TDNB của thành viên HTXNN. Mô hình không có hiện tượng phương sai sai số thay đổi bằng kiểm định Breusch-Pagan và không có hiện tượng đa cộng tuyến (VIF < 2).

Bảng 10 cho thấy trong 8 biến đưa vào mô hình, có 2 biến ảnh hưởng có ý nghĩa thống kê ở mức $1 \%$ và có 2 biến có ý nghĩa thống kê ở mức $5 \%$. Tham gia hội, đoàn thể và tập huấn có ảnh hưởng tỷ lệ thuận đến sự sẵn lòng tham gia đóng góp và quỹ TDNB, kết quả này cũng tương đồng với với các nghiên cứu trước đây của Nguyễn Thùy Trang và Võ Hồng Tú (2016), Nguyễn Văn Song và $c t v$. (2011). Kinh nghiệm sản xuất ảnh hưởng tỷ lệ nghịch đến sự sẵn lòng đóng góp và những thành viên của HTXNN thủy sản có mức sẵn lòng đóng góp cao nhất, những thành viên HTXNN sản xuất màu có sự sẵn lòng đóng góp thấp nhất. Sự sẵn lòng 
đóng góp cao của thành viên thuộc các HTX thủy sản có thể do nhu cầu về nguồn vốn cao hơn và khả năng về tài chính tốt hơn so với các nhóm còn lại. Đối với các thành viên HTX sản xuất rau màu do nhu cầu về vốn không cao và điều kiện tài chính của phần lớn thành viên còn khó khăn nên sự sẵn lòng tham gia đóng góp còn hạn chế.

\section{Bảng 10. Kết quả hồi quy các yếu tố ảnh hưởng đến mức sẵn lòng đóng góp vào TDNB}

\begin{tabular}{lcrr}
\hline Biến độc lập & Hệ số ước lượng & Gía trị t & VIF \\
\hline Giới tính & $48,75^{\mathrm{ns}}$ & 0,69 & 1,04 \\
Sản xuất cây ăn trái & $-104,45^{\mathrm{ns}}$ & 1.34 & 1,05 \\
Sản xuất lúa & $-145,56^{\mathrm{ns}}$ & 1.43 & 1,06 \\
Sản xuất màu & $-169,02^{* * *}$ & $-3,40$ & 1,02 \\
Tập huấn & $298,14^{* *}$ & 1.96 & 1,02 \\
Kinh nghiệm sản xuất & $-3,07^{* *}$ & $-2,13$ & 1,19 \\
Thu nhập & $-0,002^{\mathrm{ns}}$ & $-0,37$ & 1,19 \\
Tham gia hội, đoàn thể & $134,82^{* * * *}$ & 3,33 & 1,03 \\
Hằng số & 25,79 & 0,15 & \\
\hline Tống số quan sát & & & 232 \\
Hệ số R & & & 0,49 \\
Mức ý nghĩa mô hình & & & 0,000 \\
\hline
\end{tabular}

Nguồn: Số liệu khảo sát năm 2018, n=244

Ghi chú: ***, ** làn luợt thể hiện mức ý nghĩa 1\% và 5\%, ", không có ý nghĩa thống kê

Ghi chú: nhũng thành viên thủy sản được làm co sở (reference)

\section{KẾT LUẬN VÀ KIẾN NGH!}

\subsection{Kết luận}

Kết quả nghiên cứu cho thấy các hoạt động của HTXNN tỉnh Vĩnh Long còn nhỏ về quy mô thị trường, cụ thể là còn đến hơn $30 \%$ HTX hoạt động ở quy mô cấp huyện trở xuống. Số lượng thành viên tham gia HTX còn ít, trung bình chỉ khoảng 23 thành viên/HTX, vốn điều lệ còn rất hạn chế, chỉ khoảng 223 triệu đồng/HTX. Phần lớn các HTX hoạt động đơn dịch vụ, chiếm đến $82,8 \%$. Các dịch vụ chủ yếu của HTXNN tỉnh là tiêu thụ sản phẩm, cung cấp vật tư nông nghiệp. Theo kết quả phân loại HTX, tỷ lệ yếu, kém và trung bình vẫn chiếm tỷ trọng khá cao, khoảng $65 \%$. Kết quả này cho thấy hiệu quả hoạt động của các HTXNN tỉnh Vĩnh Long còn rất hạn chế.

Các HTXNN trên địa bàn tỉnh Vĩnh Long chưa thành lập quỹ TDNB do còn nhiều khó khăn và thiếu thốn về cơ sở vật chất, trụ sở làm việc, nguồn tài chính không đủ thành lập quỹ. Tuy nhiên, kết quả nghiên cứu cho thấy phần lớn HTXNN và thành viên đều có nguyên vọng thành lập quỹ TDNB, cụ thể có đến $62,1 \%$ các HTX đồng ý thành lập quỹ và $81,97 \%$ thành viên được phỏng vấn trả lời sẽ sẵn sàng tham gia vào quỹ TDNB. Về mức sẵn lòng đóng góp của các thành viên rất khác nhau trong từng lĩnh vực sản xuất; do vậy, hình thức vận đóng đóng góp quỹ hàng tháng có thể tùy theo khả năng tài chính của từng thành viên trong HTX.
Kết quả mô hình Probit có 4 yếu tố ảnh hưởng đến sự sẵn lòng tham gia vào quỹ TDNB, trong đó có 3 yếu tố ảnh hưởng tỷ lệ thuận: tham gia tập huấn, diện tích đất nông nghiệp và tham gia vào hội, đoàn thể địa phương và một yêu tố ảnh hưởng tỷ lệ nghịch là kinh nghiệm sản xuất nông nghiệp của thành viên.

Kết quả của mô hình hồi quy OLS cũng cho thấy có 4 yếu tố ảnh hưởng đến sự sẵn lòng đóng góp vào quỹ TDNB: 2 yếu tố ảnh hưởng tỷ lệ thuận là tham gia vào hội, đoàn thể; tham gia tập huấn và một yếu tố ảnh hưởng tỷ lệ nghịch là kinh nghiệm sản xuất. Kết quả hồi quy OLS cũng cho thấy những thành viên của HTXNN thủy sản có mức sẵn lòng đóng góp cao nhất, những thành viên HTXNN sản xuất màu có sự sẵn lòng đóng góp thấp nhất.

\subsection{Kiến nghị}

Từ kết quả nghiên cứu, để khuyến khích sự tham gia của các thành viên vào quỹ TDNB, một số kiến nghị cụ thể như sau:

- Phần lớn các HTXNN và thành viên đều có nguyện vọng thành lập quỹ TDNB, các cơ quan quản lý như Chi cục Phát triển Nông thôn và Liên minh HTX tỉnh nên hướng dẫn cụ thể quy trình thành lập, cách thức vận hành và quản lý quỹ TDNB cho các HTX nông nghiệp. Bên cạnh đó, cần hướng dẫn cụ thể về cơ chể bảo toàn vốn và lãi suất cho vay, huy động để tăng niềm tin và tính thu hút cho các thành viên tham gia đóng góp. 
- Về mức quỹ đóng góp, tùy theo tình hình hoạt động và đặc điểm kinh tế - xã hội của từng HTXNN cũng như từng thành viên, các cơ quan quản lý có thể đề xuất mức quỹ đóng góp hàng tháng cho phù hợp. Hình thức thành lập và đóng góp quỹ hàng tháng có thể tùy theo năng lực tài chính của từng thành viên. Tuy nhiên, thành viên của HTX rau màu thường có mức sẵn lòng đóng góp thấp và thành viên HTX thủy sản có mức sẵn lòng đóng góp cao.

- Xem xét thực hiện mô hình thí điểm ở những HTX có thành viên tích cực tham gia tập huấn, chia sẻ kiến thức, kinh nghiệm cũng như có thành viên tham gia trong các tổ chức đoàn hội để làm điển hình cho các HTX khác học tập kinh nghiệm.

- Tiếp tục lồng ghép nội dung thành lập và phát triển quỹ TDNB trong các lớp tập huấn, cụ thể là cho các thành viên trong HTX, đặc biệt là thành viên lớn tuổi và có nhiều kinh nghiệm để thấy được tầm quan trọng của quỹ trong phát triển HTX cũng như kinh tế cho các thành viên, đặc biệt là thành viên gặp khó khăn về tài chính.

- Những thành viên HTXNN là cán bộ hội, đoàn thể cần phát huy vai trò tuyên truyền và nâng cao nhận thức cho các thành viên về quỹ TDNB trong các buổi họp hoặc sinh hoạt định kỳ.

\section{TÀI LIỆU THAM KHẢO}

Bộ Nông nghiệp và Phát triển Nông thôn (2019). Củng cố, nâng cao hiệu quả hoạt động các HTX nông nghiệp thích ứng với cơ chế thị trường, ứng phó biển đồi khí hậu vùng ĐBSCL. Kỷ yếu Hội thảo khoa học, ngày 16/04/2019, Đồng Tháp.

Chi cục Phát triển Nông thôn tỉnh Vĩnh Long (2020). Danh sách Hợp tác xã nông nghiệp - thủy sản 2019. Sở Nông nghiệp và Phát triển Nông thôn tỉnh Vĩnh Long.

Dương Ngọc Thành, Nguyễn Công Toàn \& Hà Thị Thu Hà (2018). Đánh giá yếu tố ảnh hưởng đến hiệu quả hoạt động hợp tác xã nông nghiệp tỉnh An Giang. Tap chi khoa hoc Truờng Đại họ Cần Tho', 4(2018), 212-219.

Dương Ngọc Thành, Nguyễn Công Toàn, Nguyễn Quang Tuyến, Trương Hồng Võ Tuấn Kiệt, Lê Cảnh Dũng \& Lâm Huôn (2016). Nghiên cứu năng lực, hiệu quả sản xuất và xu hướng phát triển HTXNN trong bối cản thực hiện tái cơ cấu nông nghiệp ở ĐBSCL. Đề tài nghiên cứu cấp Bộ, Trường Đại học Cần Thơ.

Hà Thị Thu Hà (2017). Đánh giá yếu tố ảnh hưởng đến hoạt động hợp tác xã nông nghiệp tỉnh An Giang (Luận văn thạc sĩ). Trường Đại học Cần Tho.

Hoàng Tuấn (2019). Vì sao hợp tác xã ở Đồng bằng sông Cửu Long không lớn lên nổi? Thời báo
Kinh tế Việt Nam. Ngày truy cập 05/09/2020. Địa chỉ http://vneconomy.vn/vi-sao-hop-tac-xao-dong-bang-song-cuu-long-khong-lon-len-noi20190527094630006.htm.

Khai, H.V., \& Yabe, M. (2015). Consumer preferences for agricultural products considering the value of biodiversity conservation in the Mekong Delta, Vietnam. Journal for Nature Conservation, 25, 62-71.

Khưu Bảo Châu (2017). Phân tích các yếu tố ảnh huởng đến quyết định tham gia vào hợp tác xã nông nghiệp của nông hộ tỉnh Vĩnh Long (Luận văn thạc sĩ). Trường Đại học Cần Thơ.

Kontoleon, A., \& Yabe, M. (2006). Market segmentation analysis of preferences for GM derived animal foods in the UK. Journal of Agricultural \& Food Industrial Organization, 4(1).

Kotchen, M.J. (2005). Impure public goods and the comparative statics of environmentally friendly consumption. Journal of Environmental Economics and Management, 49(2), 281-300.

Mekong Connect (2019). Bắt mạch xu hướng thị trường định hướng cho nông sản đồng bằng. Kỷ yếu hội thảo, ngày 07/11/2019, Cần Thơ. Địa chỉ http://mekongconnect.vn/.

Nguyễn Công Bình (2011). Mô hình phát triển hợp tác xã nông nghiệp từ một số quốc gia. Nội san Truờng Cán bộ quản lý Nông nghiệp và PTNT 2, 1(2011).

Nguyễn Thanh Thửa (2018). Đánh giá thưc trang và các yếu tố ảnh hưởng đến hiệu quả hoạt động hợp tác xã nông nghiệp tỉnh Đồng Tháp (Luận văn thạc sĩ). Trường Đại học Cần Thơ.

Nguyễn Thùy Trang và Võ Hồng Tú (2016). Nhận thức và sự sã̃n lòng đóng góp của nông hộ cho chương trình xây dựng nông thôn mới tại tỉnh Hậu Giang. Tạp chí Khoa học Truờng Đại học Cần Tho, 46(2016), 96-103.

Nguyễn Thùy Trang \& Võ Hồng Tú (2016). Nhận thức và sự sẵn lòng đóng góp của nông hộ cho chương trình xây dựng nông thôn mới tại tỉnh Hậu Giang. Tạp chi Khoa học Truờng Đại học Cần Tho, 46c, 96-103.

Nguyễn Văn Đệ (2013). Phân tích hiệu quả hoạt động của hợp tác xã tại tỉnh Trà Vinh (Luận văn thạc sĩ). Trường Đại học Cần Thơ.

Nguyễn Văn Song, Nguyễn Thị Ngọc Thương, Đào Thị Hồng Ngân, Phạm Thị Hương, Đỗ Thị Minh Thùy \& Chử Đức Tuấn (2011). Xác định mức sẵn lòng chi trả của các hộ nông dân vê dịch vụ thu gom, quản lý và xử lý chất thải rắn sinh hoạt ở địa bàn huyện Gia Lâm - Hà Nội. Tạp chí Khoa học và Phát triển, 9(5), 853-860.

Nguyễn Văn Tuấn (2019). Phát triển hợp tác xã nông nghiệp tỉnh Bạc Liêu (Luận văn thạc sỹ). Trường Đại học Cần Thơ. 
Phạm Thị Minh Nguyệt (2006). Giáo trình kinh tế hợp tác trong nông nghiệp. Nhà xuất bản Nông nghiệp.

Phan Trọng An (2007). Kinh nghiệm phát triển HTXNNNN ở Nhật Bản và bài học rút ra cho Việt Nam. Trường Đại học Kinh tế, Thành Phố Đà Nẵng.
Quốc hội Nước Cộng hòa Xã hội Chủ nghĩa Việt Nam, 2012. Luật Hợp tác xã, số 23/2012/QH13.

Tu, V. H., Can, N. D., Takahashi, Y., Kopp, S. W., \& Yabe, M. (2018). Modelling the factors affecting the adoption of eco-friendly rice production in the Vietnamese Mekong Delta. Cogent Food \& Agriculture, 4(1). 